\title{
Hysteresis controller based on a circular error area table applied to a variable speed renewable energy system
}

\author{
J. F. Sanz ${ }^{1,2}$, J. Sallán ${ }^{1,2}$, M. A. Alonso ${ }^{1}$, M. Sanz ${ }^{1,2}$, J. L. Villa ${ }^{2}$ \\ ${ }^{1}$ CIRCE Foundation. \\ C/ María de Luna 3, 50018 Zaragoza \\ e-mail: jfsanz@unizar.es, jsallan@unizar.es,.msanz@unizar.es \\ ${ }^{2}$ Departamento de Ingeniería Eléctrica. Universidad de Zaragoza. \\ C/ María de Luna 3, 50018 Zaragoza. Tel. Nr. (+34) 976762403. \\ e-mail: jvilla@unizar.es
}

\begin{abstract}
Nowadays the proliferation of renewable energies has the problem of the limited capacity of the grid to absorb these types of energies due to their low quality.

In order to increase their penetration in the electrical system it is mandatory to improve the control of the power stages used to inject the generated power and, in many cases, to achieve variable speed operation.

The paper proposes a new current control method based on a switching table that keeps the current error in a circular area and compares it with other table hysteresis control [1],[2]. As it is shown, both the THD and the frequency is better in the proposed method.
\end{abstract}

\section{Key words}

Distributed power generation, power quality, renewable energies, current controllers, table hysteresis controllers.

\section{Introduction}

Power generation is evolving from large generating facilities connected to the utility towards small generating units connected to medium and low voltage grids [3],[4]

Besides, the connection of distributed generation systems to weak grids and micro-grids is becoming more important, due to the improvement of the technical characteristics of those systems [5]. The connection of these generation systems can, if done in appropriate technical conditions, improve the behaviour of the utility where they are connected or, on the other hand, if they do not take into account some conditions, they can worsen its behaviour.

Harmonic content is one of the most important problem when dealing with the connection of variable speed generation system to weak grid, by means of power electronics [5],[6]. There are many method to soften their effects, based in high switching frequency and appropriate filtering techniques [7]-[9] although that implies an increase in the cost of the system [10].
The techniques that imply a fewer cost are the ones directly applied to the control of the generating system because they do not require any extra components.

The use of voltage converters (VSI) in the DC/AC conversion is the most widely used [11]. There are many current control methods [11],[12]. Among them, the hysteresis controllers are the simplest and the ones showing a better dynamic response, independent to load variations, with good stability, allowing a high precision and can be applied to the full operation range. Moreover, its implementation does not require knowing the parameters of the load. It can be implemented with analogical techniques and does not need any computational effort. However, they show some drawbacks [13]. Many controllers have been developed to solve the problems.

The methods more widely used are vector controllers that allow the use of zero vectors $\left(\mathrm{V}_{0}\right.$ and $\left.\mathrm{V}_{7}\right)$ in a selective way. Among them, the ones based on a table have a large acceptance because of their simplicity.

The paper compares two table-based control methods. The first one is the one described in [1],[2], and uses hexagonal shape of the error area. The second one method proposed in this paper generates a 360x360 table using an algorithm that calculates the state that minimizes the switching frequency and uses circular error area.

\section{Vector hysteresis control}

The hysteresis controller tries to keep current between to specified values called hysteresis band [11]. They compare the current reference $i_{a b c}^{*}$ and the actual current $i_{a b c}$, obtaining the error in each phase, $\varepsilon_{a b c}$, independently, using three hysteresis comparators, one in each phase.

However, in the hysteresis vector controls, the decision of the commutation state is taken considering the bridge a global element and not the result of the state of every branch, selecting one of the eight possible states. 
In order to do this, the VSI is analysed in the complex field. Using this method, the time variables of three phase current and voltage $\left(i_{a b c}, v_{a b c}, e_{a b c}\right)$ are represented as space vectors in the stationary components $\alpha-\beta$, obtaining the vector voltage and current $\bar{V}=v_{\alpha}+j \cdot v_{\beta}$, $\bar{I}=i_{\alpha}+j \cdot i_{\beta}$, using Clark transform:

$$
\left[\begin{array}{l}
v_{\alpha} \\
v_{\beta}
\end{array}\right]=\left[\begin{array}{ccc}
\frac{1}{2} & \frac{-1}{3} & \frac{-1}{3} \\
0 & \frac{1}{\sqrt{3}} & \frac{-1}{\sqrt{3}}
\end{array}\right] \cdot\left[\begin{array}{c}
v_{a} \\
v_{b} \\
v_{c}
\end{array}\right]
$$

The number of switching states is limited to 8, generating eight voltage vectors $\left(\bar{V}_{0} \ldots \bar{V}_{7}\right)$. The graphic representation of the 8 states is shown in figure 1 .

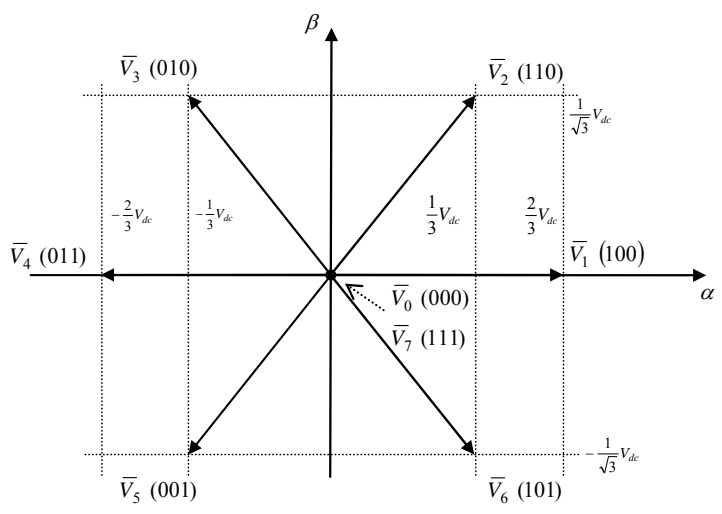

Fig. 1 Graphic representation of the switching states

Vectors zero and eleven are located in the origin because its value is zero. This way, the vector space is divided into six areas or sectors of $60^{\circ}$ each. Area 1 (A1) si limited by vectors $\bar{V}_{1}$ y $\bar{V}_{2}$, A2 by $\bar{V}_{2}$ y $\bar{V}_{3}$, and so on.

Figure 2 shows the equivalent circuit of the system. The derivative of the bridge output current phasor, neglecting the voltage drop in the inductor's resistance, is:

$$
\frac{d \bar{I}}{d t}=\frac{1}{L}\left(\bar{V}_{p}-\bar{E}\right)
$$

Where $\mathrm{L}$ is the value of the output inductance, $\bar{V}_{p}$ is the bridge voltage phasor and $\bar{E}$ is the gird voltage phasor.

Besides, the desired bridge current value $\bar{I}^{*}$ forms the current reference phasor, whose equation is

$$
\frac{d \bar{I}^{*}}{d t}=\frac{1}{L}\left(\bar{V}^{*}-\bar{E}\right)
$$

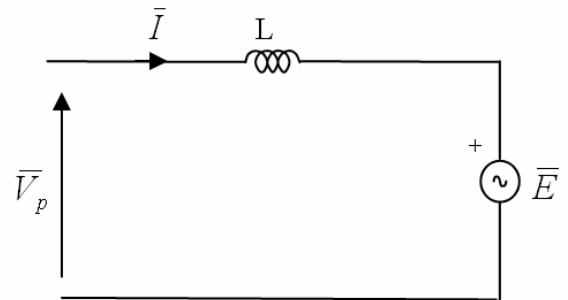

Fig. 2. Equivalent circuit

Where $\bar{V}^{*}$ is the output voltage phasor that would make possible to achieve the desired output current.

$$
\bar{V}^{*}=L \frac{d \bar{I}^{*}}{d t}+\bar{E}
$$

However, the output voltage can only take eight values and thus the current output does not follow the reference perfectly, and the difference between these phasors gives the current error phasor. $\bar{\varepsilon}=\bar{I}^{*}-\bar{I}$. Thus, the derivative of this error is:

$$
\frac{d \bar{\varepsilon}}{d t}=\frac{d \bar{I}^{*}}{d t}-\frac{d \bar{I}}{d t}=\frac{1}{L}\left(\bar{V}^{*}-\bar{V}_{p}\right)
$$

And the switching state for the bridge is obtained from:

$$
\bar{V}_{p}=\bar{V}^{*}-L \frac{d \bar{\varepsilon}}{d t}
$$

\section{A. Hexagonal hysteresis control}

This control [1], [2] consist of a table-based hysteresis control that uses a two-level comparator in each phase, giving a hexagonal error area, just like in the conventional hysteresis control. The obtained table is based in the identification of the position of both the reference voltage phasor and the current error every time one of the currents reaches the band.

To do this, the voltage space is divided into six sectors $\left(\mathrm{S}_{\mathrm{v}}\right)$ and the current error space in another six $\left(\tilde{\mathrm{S}_{\varepsilon}}\right)$ For each current error sector, a voltage vector that reduces this error is taken, intending to keep the voltage difference as low as possible in order to reduce switching frequency. The graphic procedure is explained in the papers, and the result is shown in table 1 and figure 3 .

\begin{tabular}{|c|c|c|c|c|c|c|}
\hline Sector & $\mathrm{S}_{\mathrm{v} 1}$ & $\mathrm{~S}_{\mathrm{v} 2}$ & $\mathrm{~S}_{\mathrm{v} 3}$ & $\mathrm{~S}_{\mathrm{v} 4}$ & $\mathrm{~S}_{\mathrm{v} 5}$ & $\mathrm{~S}_{\mathrm{v} 6}$ \\
\hline $\mathrm{S}_{\alpha 1}$ & 0,7 & 0,7 & 1 & 1 & 2 & 2 \\
\hline $\mathrm{S}_{\alpha 2}$ & 3 & 0,7 & 0,7 & 2 & 2 & 3 \\
\hline $\mathrm{S}_{\alpha 3}$ & 4 & 4 & 0,7 & 0,7 & 3 & 3 \\
\hline $\mathrm{S}_{4 \alpha 4}$ & 4 & 5 & 5 & 0,7 & 0,7 & 4 \\
\hline $\mathrm{S}_{\alpha 5}$ & 5 & 5 & 6 & 6 & 0,7 & 0,7 \\
\hline $\mathrm{S}_{\alpha 6}$ & 0,7 & 6 & 6 & 1 & 1 & 0,7 \\
\hline
\end{tabular}

Table 1 .- Static table for the hexagonal hysteresis control. 


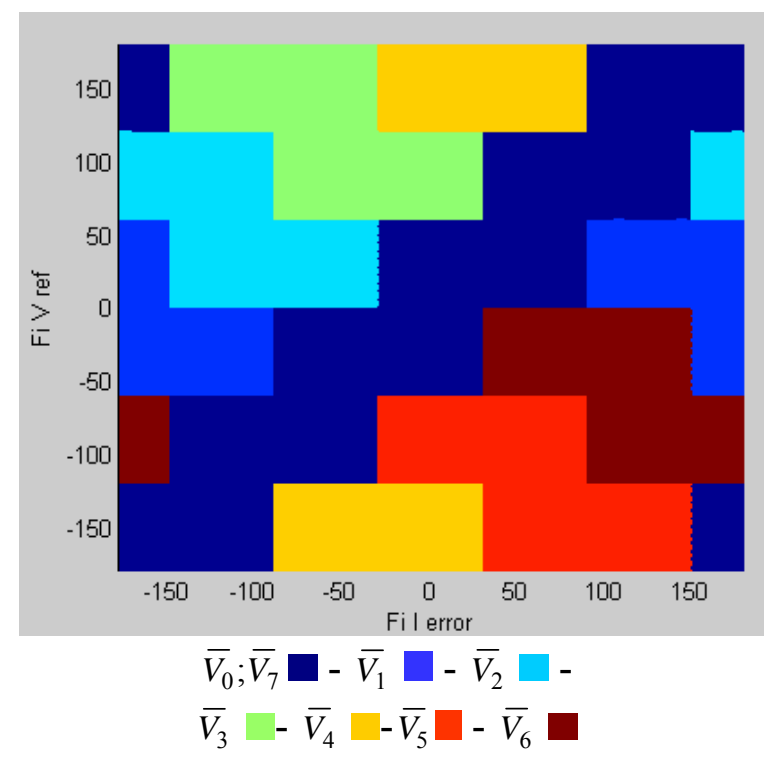

Fig. 3. Graphic representation of the static table for the hexagonal hysteresis control.

Considering that in some occasions the error can grow beyond the limit imposed by the band, in order for it to return to the limits, a second table is used, referred by the authors as "dynamic table". The switching vectors in this table are those that more quickly reduce the error, taking into account just the position of the reference voltage.

\begin{tabular}{|c|c|c|c|c|c|c|}
\hline Sector & $\mathrm{S}_{\mathrm{v} 1}$ & $\mathrm{~S}_{\mathrm{v} 2}$ & $\mathrm{~S}_{\mathrm{v} 3}$ & $\mathrm{~S}_{\mathrm{v} 4}$ & $\mathrm{~S}_{\mathrm{v} 5}$ & $\mathrm{~S}_{\mathrm{v} 6}$ \\
\hline $\bar{V}_{p}$ & 4 & 5 & 6 & 1 & 2 & 3 \\
\hline
\end{tabular}

Table 2.- Dynamic Table for the hexagonal hysteresis control.

\section{B. Circular hysteresis control}

If, instead of using a hysteresis comparator for each phase, a single comparator for the current error phasor is used, the error area becomes a circle. This error area has been used in [14].

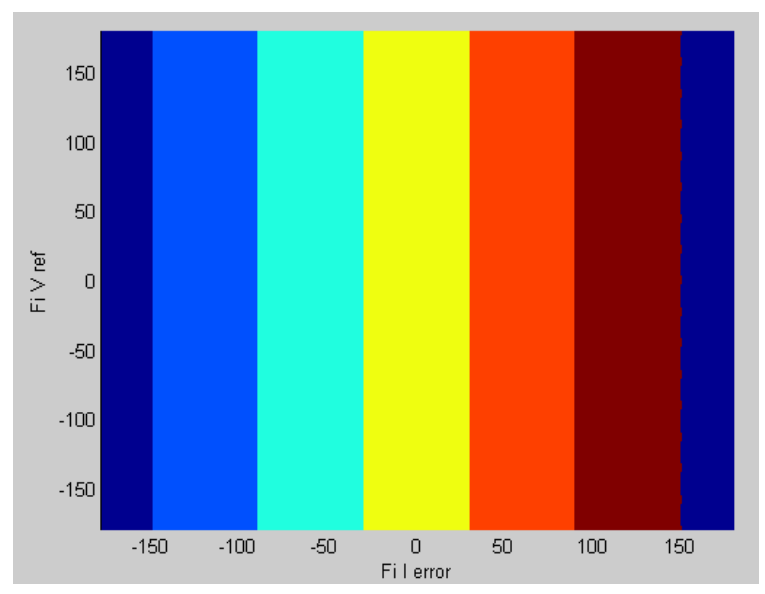

Fig. 4. Graphic representation of the dynamic table for the hexagonal hysteresis control.
Moreover, instead of using a 6x6 table, a 360x360 table has been used. The switching vector is obtained for every degree of both the reference voltage phasor angle and the current error phasor angle.

To do this, the direction that the current phasor and its speed is computed for each switching state. This direction is given by a line $\left(M_{\bar{I}}\right)$ whose origin is located at the initial position of the current phasor $\left(\bar{I}_{0}=i_{0 \alpha}+j \cdot i_{0 \beta}\right)$ and whose variation is obtained from the derivative of the error phasor:

$$
M_{\bar{I}}=\bar{I}_{0}+\frac{d \bar{\varepsilon}}{d t} t=\left(i_{0 \alpha}+\frac{d \varepsilon_{0 \alpha}}{d t} t\right)+j \cdot\left(i_{0 \beta}+\frac{d \varepsilon_{0 \beta}}{d t} t\right)
$$

The initial position off phasor $\bar{I}$ is located in the circumference whose centre is the reference current $\left(\bar{I}^{*}=i_{\alpha}^{*}+j \cdot i_{\beta}^{*}\right)$ and whose radius is the tolerance band $\mathrm{B}$, as shown in figure 5 .

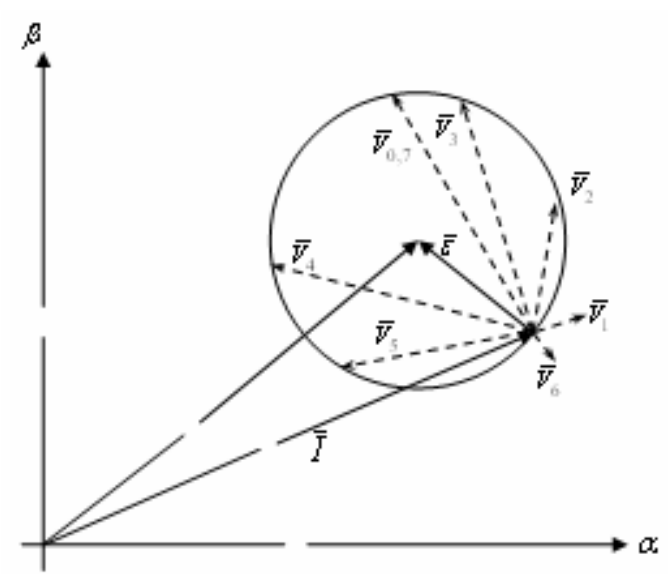

Fig. 5. Graphic representation of the selection procedure

The equation for the circumference is:

$$
\left(i_{\alpha}-i_{\alpha}^{*}\right)^{2}+\left(i_{\beta}-i_{\beta}^{*}\right)^{2}=B^{2}
$$

Calculating the intersection of the line with the circumference, for each switching state, the time required for this intersection is computed and the state that maximises this time is taken, forming the "static table".

At the same time, the switching state that makes line $M_{\bar{I}}$ pass as close as possible from the centre of the circumference is stored, forming the "dynamic table"

The input data for the calculation of both tables are the effective grid voltage, the maximum effective current, the band value and the inductance. The results are shown in figures 6 and 7. 


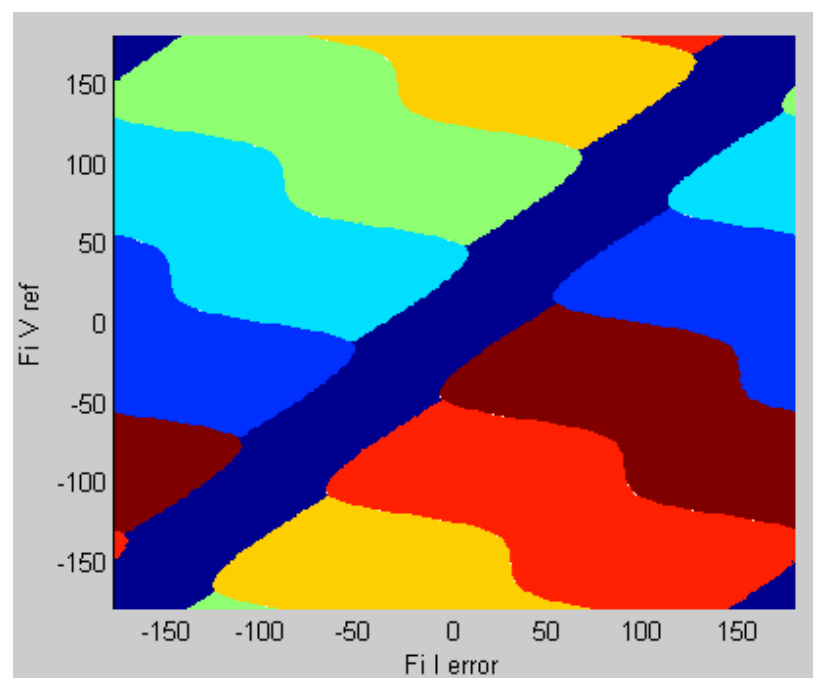

Fig. 6. Graphic representation of the static table for the circular hysteresis control.

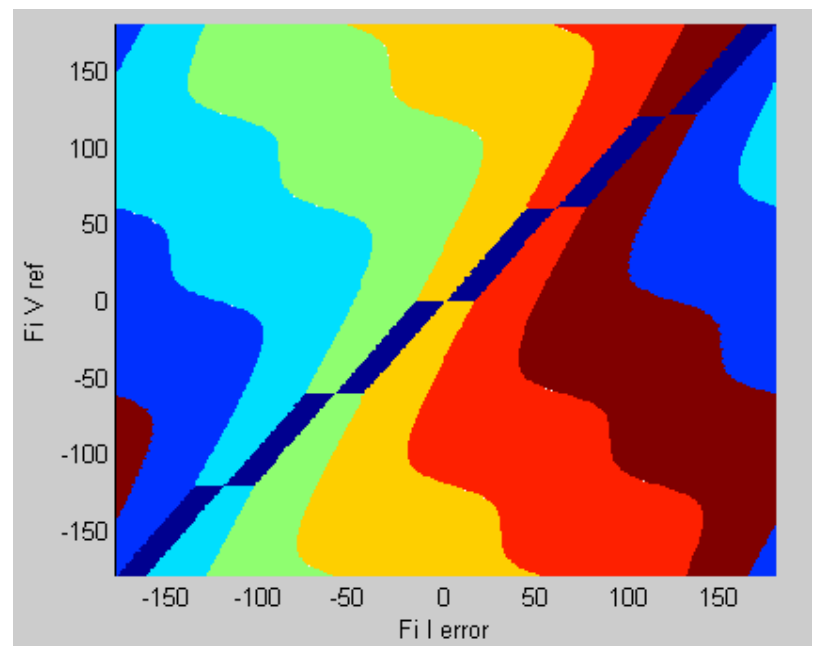

Fig. 7. Graphic representation of the static table for the circular hysteresis control.

\section{Comparison}

Both methods have been simulated using Matlab in a system connected to a grid $\mathrm{f} 400 \mathrm{~V}$, with a DC bus of 700 $\mathrm{V}$ and an inductance of $0,8 \mathrm{mH}$. The effect of the resistance has been neglected and a blocking time of $5 \mu \mathrm{s}$ has been implemented.

In order to test their behaviour under various conditions, test at 650, 350 and 150 Amperes have been performed. The internal and external bands are $10 \%$ and $12 \%$ of the reference current respectively.

The tests have been carried out varying the DC voltage from $710 \mathrm{~V}$ down to the minimum value required for the bridge to operate properly. Every voltage level has been kept for 0,2 seconds and the test has been repeated at least 4 times.
Comparing both static tables (fig 3 and 6) it can be noticed that they differ in $17,6 \%$ of the data., whereas the dynamic tables differ in up to $47,75 \%$. This makes that the behaviour of the bridge with the circular control is better than with the hexagonal control.

At high current levels the static table of the circular method always finds a switching vector that keeps the error within the desired area. However, in the hexagonal method, the dynamic table has to be used. As current decreases (switching frequency increases) the number of times when the dynamic table is used increases in both cases. In these occasion, using the circular method (figure 8 ) ensures that the vector returns to the desired area, whereas using the hexagonal method does not (figure 9).

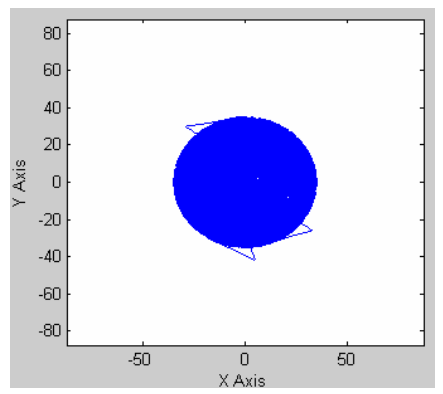

Fig. 8 Representation of the circular error phasor. $\mathrm{I}_{\mathrm{out}}=350 \mathrm{~A}$, $\mathrm{B}=35 \mathrm{~A}, \mathrm{Vdc}=690 \mathrm{~V}$.

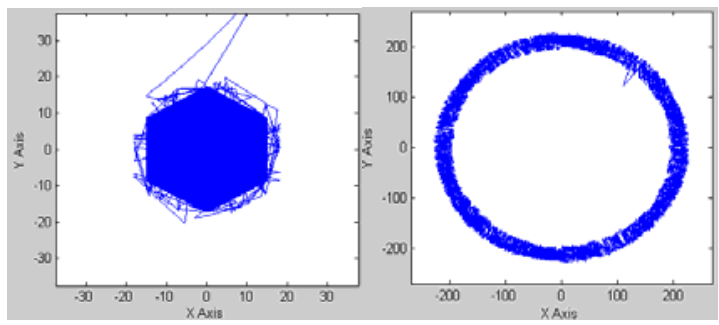

Fig. 9 Representation of the error and current phasors with hexagonal control. $\mathrm{I}_{\text {out }}=350 \mathrm{~A}, \mathrm{~B}=35 \mathrm{~A}, \mathrm{Vdc}=690 \mathrm{~V}$.

On top of that, with the hexagonal error area some situations with high switching frequency occur when the current error gets stuck in a vertex. This is one of the reasons why the error current phasor leaves the inner band in the hysteresis current control method.

Besides, figure 10 shows that the value of the harmonic distortion obtained using the second method is always better.

The switching frequency is highly influenced by the dc voltage, being possible to find an optimum value as a function of the current supplied to the grid.

The main difference between both methods is that the circular hysteresis control makes it possible to operate with lower dc voltages, which allows a lower switching frequency. 


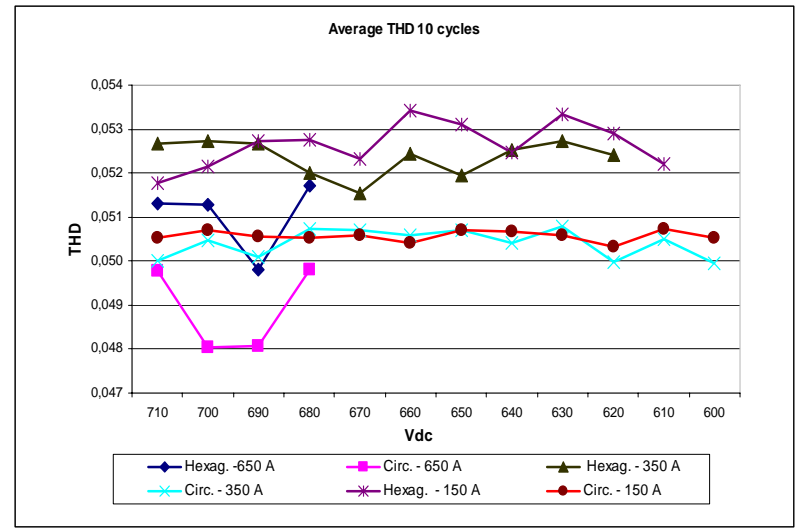

Fig. 8 Average THD in 10 cycles for both methods at different output currents and different dc voltages.

Moreover, its behaviour almost does not change in the repeated simulations, having a similar number of switching in each phase. However, the hexagonal control shows great oscillations in the switching frequency, with noticeable differences among phases, being sometime even double.

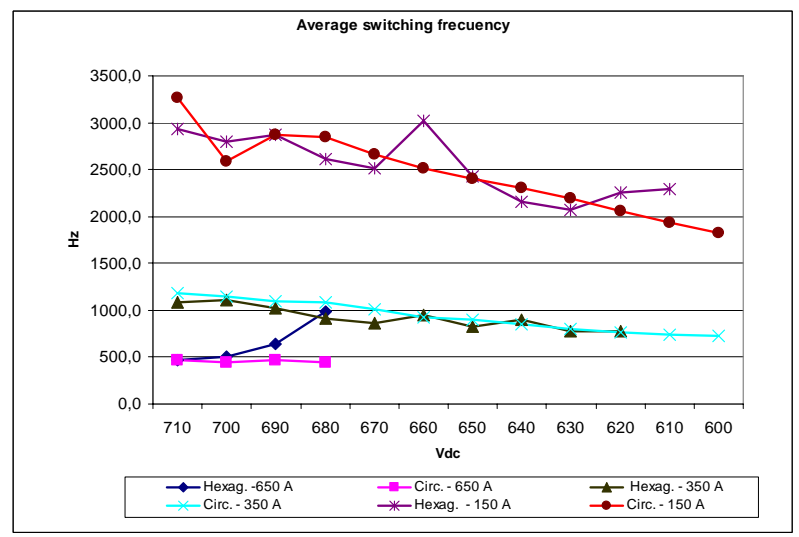

Fig. 9 Average switching frequency for both methods at different output currents and different dc voltages.

Lastly, the circular method shows to be much more robust at low currents because the number of times when it reaches the safety band is always much lower than in the hexagonal control. Even in some occasions the hexagonal control has been unable of tracking the reference, causing the current to go beyond both bands.

\section{Conclusions}

The paper presents a new VSI table hysteresis current control method and compares it to another existent table method [1],[2]. The proposed method shows lower harmonic content, slightly lower switching frequency, allows operating at a lower dc voltage and it is more robust. The main drawback is that at output currents different from the one used for the calculation of the table, the error phasor leaves the desired area and reaches the dynamic band. (Always in much fewer occasions than the compared method)

\section{References}

[1] P. Eichenberger, M. Junger. "Predictive Vector Control of the Stator Voltages for an induction Machine drive with Current Source Inverter". Power Electronics Specialists Conference, 1997. PESC '97 Record., 28th Annual IEEEVolume 2, 22-27 June 1997 Page(s):1295 - 1301 vol.2

[2] Mirjana Milosevic. "Hysteresis Current Control in ThreePhase Voltage Source Inverter". Technical Report, Zurich 2003

[3] M.H.J Bollen. "What is power quality?". Electric Power Systems Research 66 (2003) 5-14

[4] B. Lasseter. "Microgrids". IEEE. Power Engineering Society Winter Meeting, 2001IEEE Volume 1, 27-31 Jan. 2002 Page(s):305 - 308 vol.1

[5] N.D. Hatziargyriou; A.P. Sakis Meliopoulus. "Distributed Energy Sources: Technical Challenges. Power Engineering Society Summer Meeting, 2001. IEEE. Volume 1, 15-19 July 2001 Page(s):548 - 550 vol.1

[6] S. A. Papathanassiou; N. D. Hatziargyriou. "Technical Requirements for the Connection of Dispersed Generation to the Grid". Power Engineering Society Summer Meeting, 2001.IEEE Volume 2, 15-19 July 2001 Page(s):749 - 754 vol.2

[7] F.D Kanellos; N.D. Hatziargyriou. "The effect of VariableSpeed Wind Turbines on the Operation of Weak Distribution Networks". Energy Conversion, IEEE. Transactions on. Volume 17, Issue 4, Dec. 2002 Page(s):543 - 548

[8] J. G. Slootweg, W.L. Kling. "Is The Answer Blowing in the Wind". Power and Energy Magazine, IEEE. Volume 1, Issue 6, Nov-Dec 2003 Page(s):26 - 33

[9] A. Sannino, J. Svensson, Y. Larsson. "Power-electronic solutions to power quality problems". Electric Power Systems Research 66, 2003

[10] T. Thiringer. "Integration of large sea-based wind parkshow much power electronic devices are needed in order to avoid power quality problems on the grid?" Power Engineering Society Summer Meeting, 2000. IEEE Volume 2, 16-20 July 2000 Page(s):1277 - 1279 vol. 2

[11] L. Malesani, P. Tomasin. "PWM Current Control Techniques of Voltage Source Converters - A Survey". Industrial Electronics, Control, and Instrumentation, 1993. Proceedings of the IECON'93 International Conference on 15-19 Nov. 1993 Page(s):670 - 675 vol.2

[12] E. Aldabas, "Clasificación de los Reguladores Trifásicos de Intensidad".VI Jornades dénginyeria electrónica JCEE' 0 Tendences en engenyeria electrónica. 2000

[13] D.M Brod, D.W. Novotny. "Current Control of VSI-PWM Inverters". IEEE Transactions on Industry Applications, Vol IA-21, N0 4, May/June 1985.

[14] E. Aldabas, L. Romeral, A. Arias, J.M. Moreno, M.G Jayne. Current controller for low harmonic distortion and low switching frequency .Electrical Machines and Systems, 20 03. ICEMS 2003. Sixth International Conference on Volume 2, 9-11 Nov. 2003 Page(s):642 645 vol. 2 . 